Japan. J. Genetics Vol. 43, No. 4: 289-298 (1968)

\title{
A CHROMOSOME STUDY IN 20 SEXUALLY ABNORMAL PATIENTS"
}

\author{
WOSAMU MARUYAMA, HACHIRO SHIMBA AND SEI-ICHI KOHNO \\ Zoological Institute, Hokkaido University, Sapporo, Hokkaido 060
}

Received May 9, 1968

Thanks to rapid advances in technical methods and enthusiastic efforts of modern cytogeneticists, our knowledge of human chromosomes has become surprisingly increased in recent years. Information is now available that various types of abnormalities of sexual development in man are associated with abnormalities of sex chromosomes. To date, chromosome studies of somatic cells are essential for differential diagnosis of sexual anomalies.

During the past ten years, a rather extensive chromosomal survey has been conducted by Professor Makino and his associates in congenital disorders and sexual maldevelopment in Japanese people with cooperation of clinicians working in many medical fields. Some 250 sexually abnormal patients were screened for chromosome abnormalities in the Makino laboratory. The results obtained for 150 cases during a period from 1959 to the end of July, 1965 were reported in two summarized papers (Makino 1964, 1966). Further additional data were presented in two recent papers (Ikeuchi and Fujimoto 1966, Shimba et al. 1967).

As a link in the above project, we present in this article the results of chromosome studies in 20 sexually abnormal patients which include 6 cases of Klinefelter's syndrome, 5 cases of male hypogonadism, 2 cases of primary amenorrhoea, one case each of azoospermia, cryptorchism, hypospadias, male pseudohermaphrodite, adrenogenital syndrome, and two females with anomalous minor labia.

\section{MATERIALS AND METHODS}

Chromosomes were observed based on short-term leucocyte cultures established from peripheral blood of patients according to Moorhead et al. (1960) with minor modifications. Case 7 provided fibroblast cultures from a skin biopsy as material in addition to leucocyte cultures. Chromosome slides were made according to the routine air-drying method of Rothfels and Siminovitch (1958) with a slight modification.

\section{RESULTS}

Diagnosis and clinical findings from each patient studied are summarized in Table 1. The results of chromosomal studies are given in Table 2. Out of 6 patients diagnosed as Klinefelter's syndrome, 3 cases (1-3) showed 47 chromosomes having an XXY sex-

1) Contribution No. 816 from the Zoological Institute, Faculty of Science, Hokkaido University, Sapporo, Japan. 


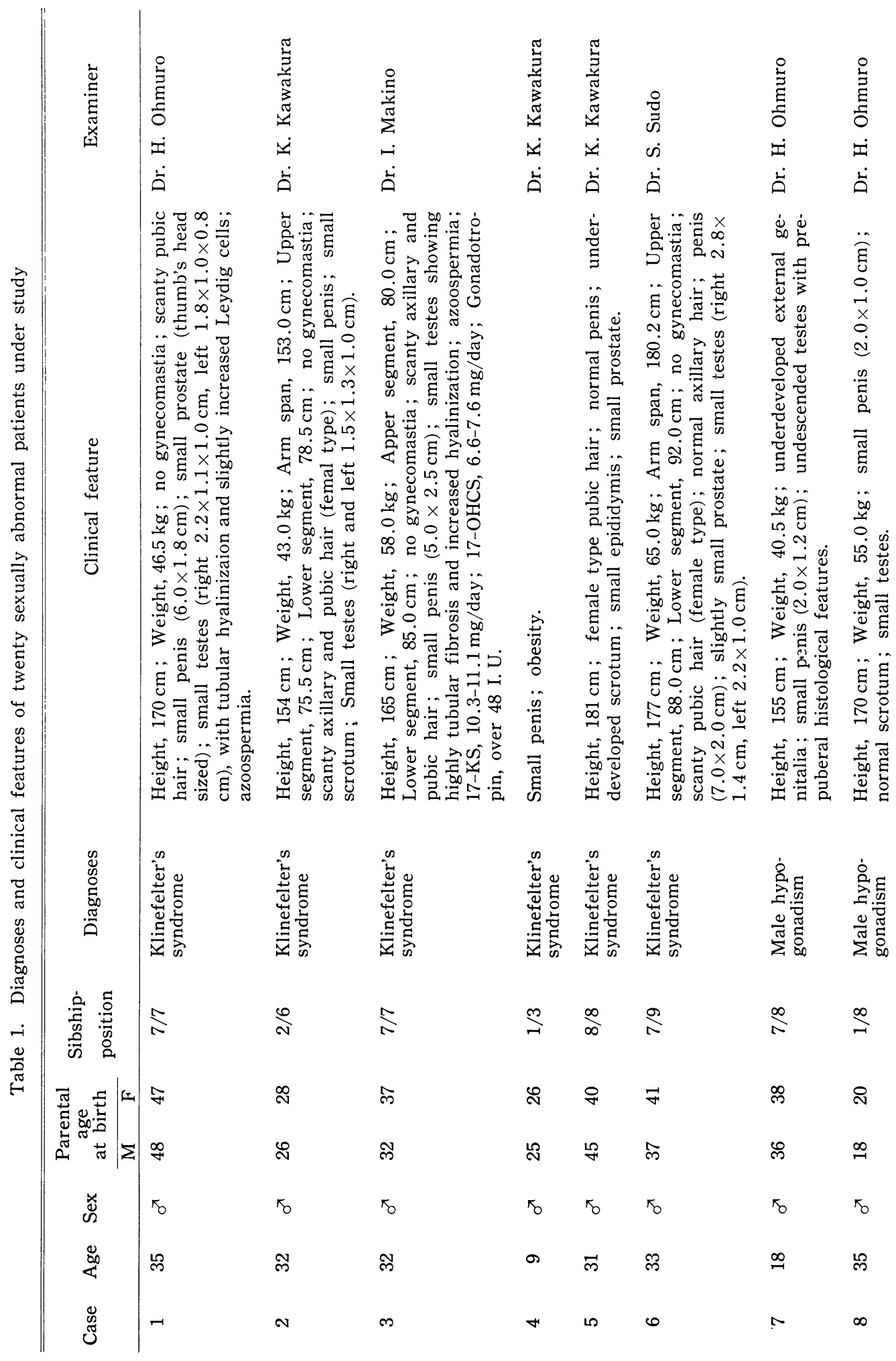




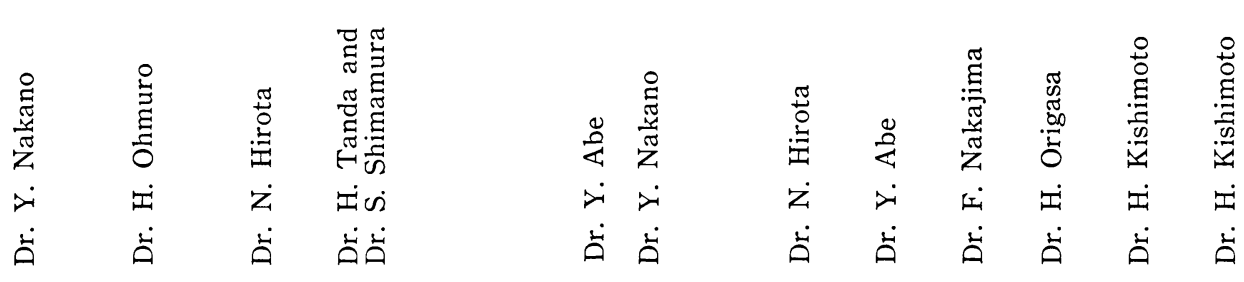

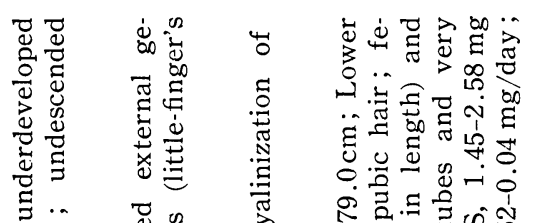

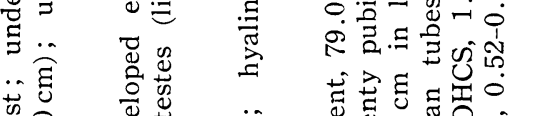

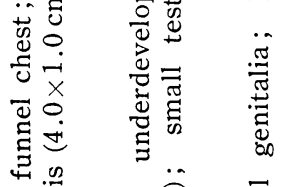

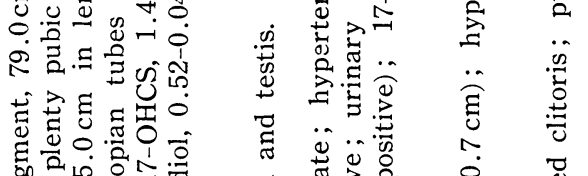

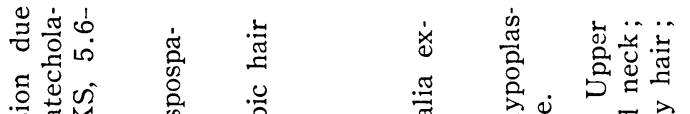

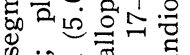

की

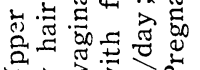

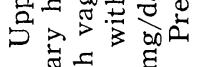

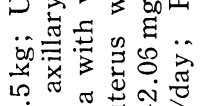

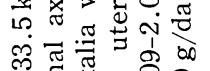

คํ

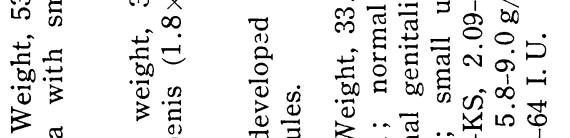

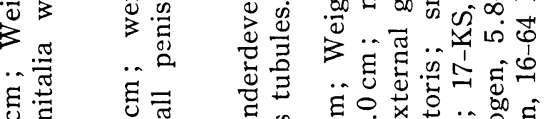

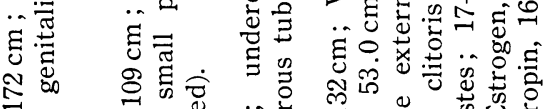

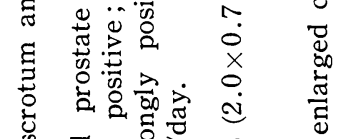

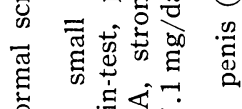

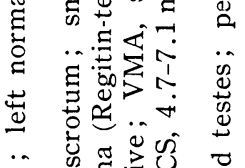

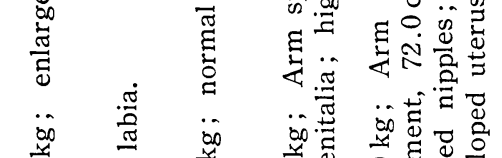

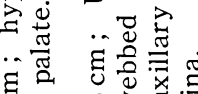

ह

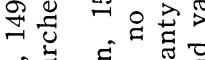

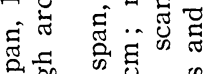

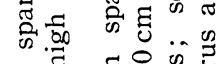

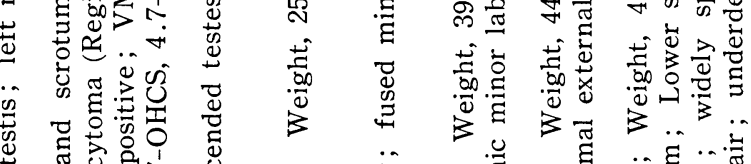

उ

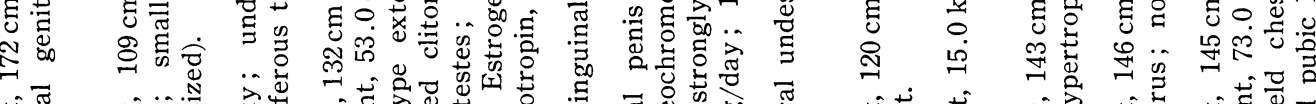

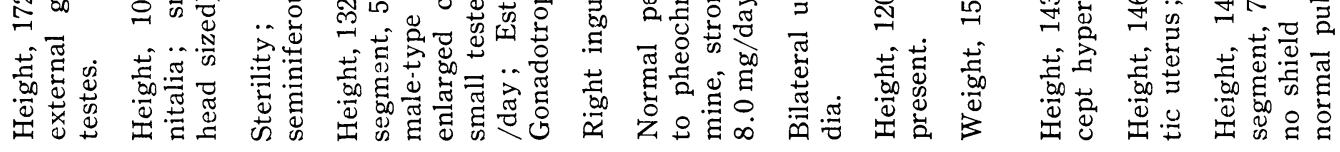

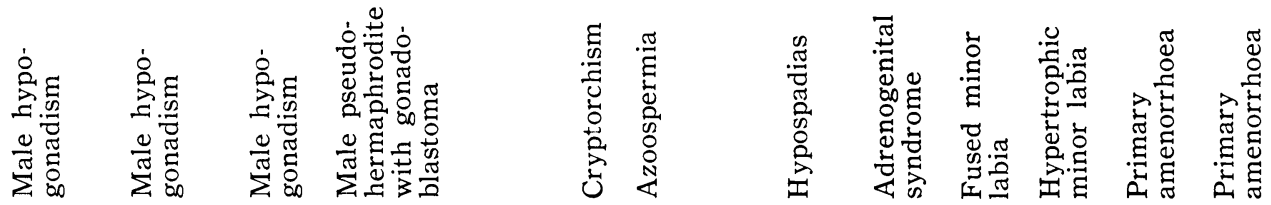

$\stackrel{m}{-} \stackrel{m}{-\infty}$

ஜ $\quad \stackrel{\infty}{\sim} \quad$ ๙

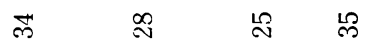

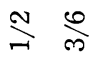

$\stackrel{\infty}{\infty}$

요 స్ల

ஜ

กิ 1 ณ ก

$r_{0} r_{0} r_{0}$ ot ot ot ot ot

$90 \%$

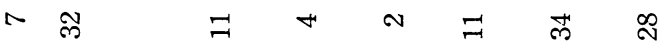

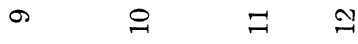

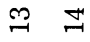

$\stackrel{2}{1} \cong$ $\stackrel{2}{\infty}$ 
Table 2. Cytological findings in cultured leucocytes of twenty sexually anomalous patients under study

\begin{tabular}{|c|c|c|c|c|c|c|}
\hline \multirow{2}{*}{ Case } & \multicolumn{4}{|c|}{ Chromosome number distribution } & \multirow{2}{*}{$\begin{array}{l}\text { No. of } \\
\text { cells } \\
\text { oberved }\end{array}$} & \multirow{2}{*}{$\begin{array}{l}\text { Chromosome } \\
\text { constitution }\end{array}$} \\
\hline & 45 & 46 & 47 & 48 & & \\
\hline 1 & 1 & 5 & 43 & & 49 & $47, \mathrm{XXY}$ \\
\hline 2 & & 2 & 37 & 1 & 40 & $47, \mathrm{XXY}$ \\
\hline 3 & & 3 & 35 & 2 & 40 & $47, \mathrm{XXY}$ \\
\hline 4 & & 3 & 10 & 89 & 102 & $48, \mathrm{XXXY}$ (long)** \\
\hline 5 & 3 & 29 & 8 & & 40 & $46, \mathrm{XY} / 47, \mathrm{XXY}$ \\
\hline 6 & 5 & 30 & 63 & 2 & 100 & $46, \mathrm{XX} / 47, \mathrm{XXY}$ \\
\hline 7 & & $\begin{array}{c}34 \\
9 *\end{array}$ & & & $\begin{array}{c}34 \\
9 *\end{array}$ & $46, \mathrm{XY}(\text { long })^{* *}$ \\
\hline 8 & & 23 & & & 23 & $46, \mathrm{XY}$ (long)** \\
\hline 9 & 1 & 12 & & & 13 & $46, \mathrm{XY}$ \\
\hline 10 & & 6 & & & 6 & $46, \mathrm{XY}$ \\
\hline 11 & 1 & 19 & & & 20 & $46, \mathrm{XY}$ (long)** \\
\hline 12 & 43 & 27 & & & 70 & $45, \mathrm{XO} / 46, \mathrm{XY}$ \\
\hline 13 & & 20 & & & 20 & $46, \mathrm{XY}$ (long)** \\
\hline 14 & 2 & 22 & & & 24 & $46, \mathrm{XY}$ \\
\hline 15 & 1 & 10 & 1 & & 12 & $46, \mathrm{XY}$ (long)** \\
\hline 16 & & 15 & & & 15 & $46, \mathrm{XX}$ \\
\hline 17 & 1 & 15 & & & 16 & $46, \mathrm{XX}$ \\
\hline 18 & 1 & 15 & & & 16 & $46, \mathrm{XX}$ \\
\hline 19 & 3 & 20 & & & 23 & $46, \mathrm{XX}$ \\
\hline 20 & 40 & 36 & 2 & & 78 & $45, \mathrm{XO} / 46, \mathrm{XX}$ \\
\hline
\end{tabular}

* Cultured fibroblasts from a skin biopsy of case 7 .

** $\mathrm{XY}$ (long) indicates an $\mathrm{X}+$ a long $\mathrm{Y}$.

determining mechanism as regular Klinefelter's syndrome. Interesting are two cases (5 and 6) which are characterized by mosaicism; one was represented by a $46, \mathrm{XY} / 47, \mathrm{XXY}$ complex and the other had a 46,XX/47, XXY constitution (Fig. 1). The remaining one (case 4) had 48 chromosomes associated with an XXXY (long) sex constitution (Fig. 2). There was a considerable number of hypomodal cells without karyotypic constancy in case 4 .

In 5 males (cases $7-11$ ) with hypogonadism, 3 cases $(7,8,11)$ had an unusually long $\mathrm{Y}$ chromosome, though the remaining elements were normal as males. Noteworthy are cases 7 and 8 (Fig. 3): They are brothers and have 2 biothers and 4 sisters. All the male members showed hypogonadism clinically similar with each other. It is interesting that the length of the $\mathrm{Y}$ chromosome in the above two cases is not identical: the length of the $\mathrm{Y}$ of case 7 (younger brother) fell without exception between 13 and 15 chromosomes in 20 randomly selected metaphase cells, while the $\mathrm{Y}$ chromosome of case 8 (elder brother) corresponded in length to $16-18$ chromosomes in 20 metaphases examined (Fig. 4). The same situation was observed in fibroblast cultures of case 7, showing the $\mathrm{Y}$ chromosome corresponding to 13-15 chromosomes. No karyotypic analysis has been undertaken in the other members. In case 11 the length of the $\mathrm{Y}$ chromosome 


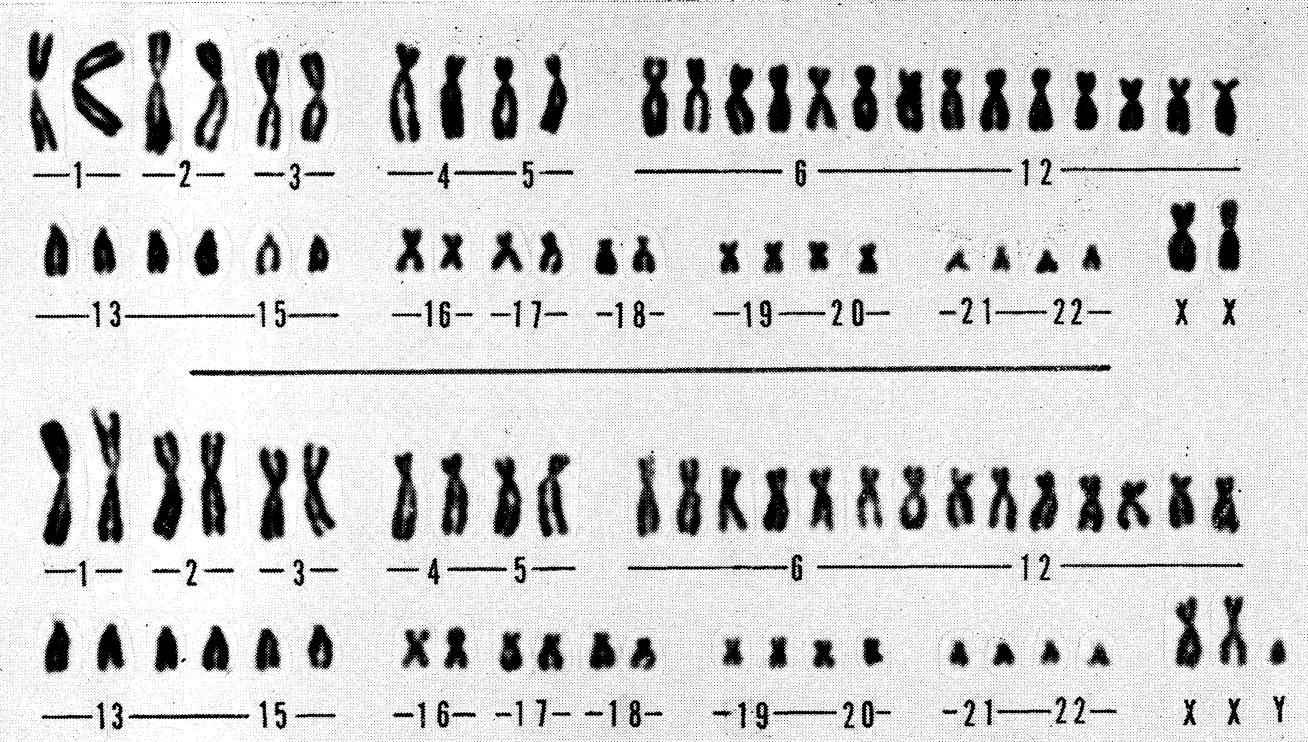

Fig. 1. Karyotype of case 6 showing a 46, XX/47, XXY mosaicism.

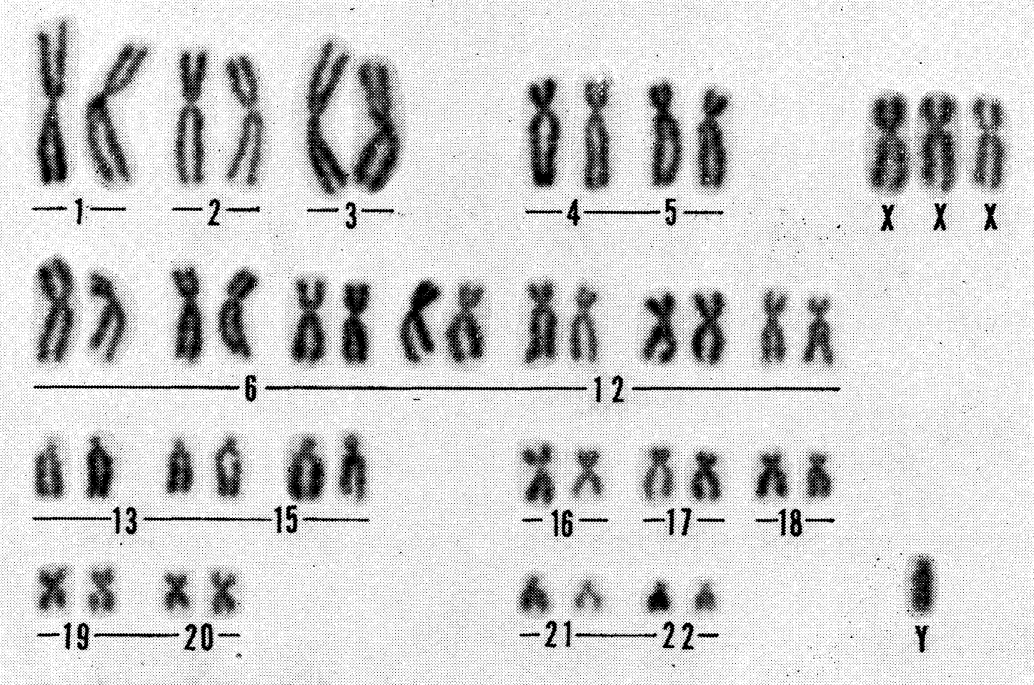

Fig. 2. Karyotype of case 4, showing a 48, XXXY (long) constitution.

corresponded approximately to chromosomes 16 . The remaining two cases (9 and 10) had a normal male karyotype (46, XY).

Case 12 was treated as a female because of the female-like external genitalia except an enlarged clitoris. On the basis of clinical and histological examinations, this case was diagnosed as male pseudohermaphroditism. Upon laparotomy this patient had a very small uterus, fallopian tubes and small testes with epididymis occurring in the place 


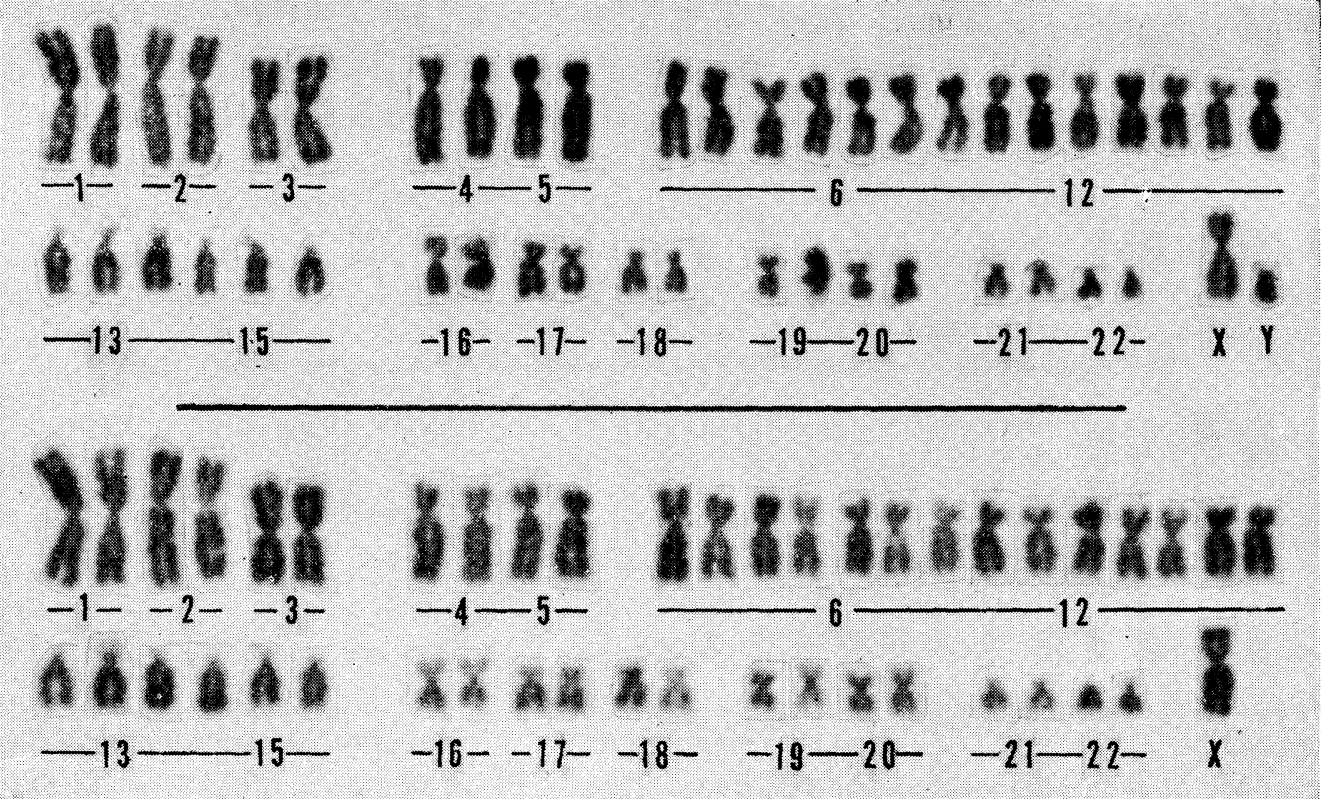

Fig. 3. Karyotype of case 12 , showing a $45, \mathrm{XO} / 46, \mathrm{XY}$ mosaicism.

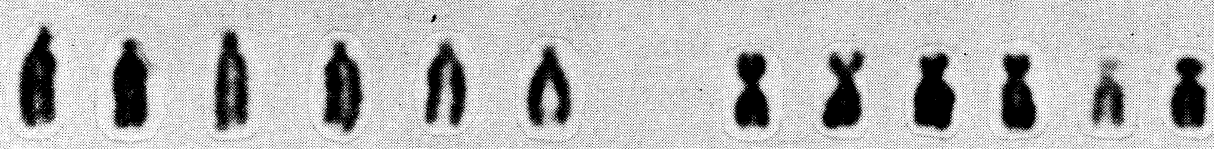

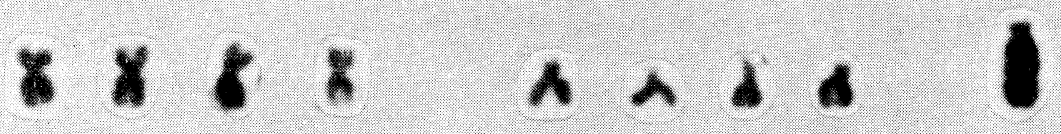

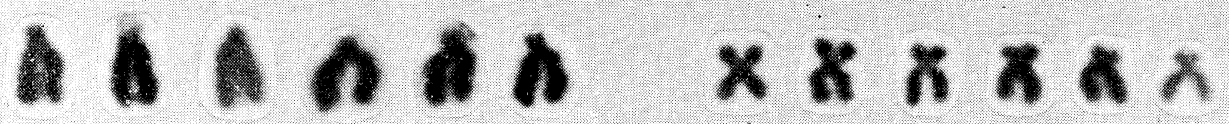

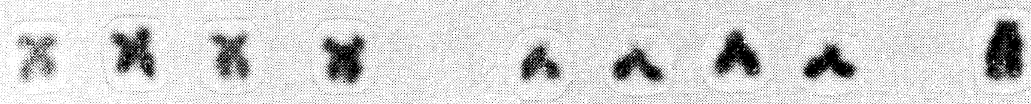

Fig. 4. Partial karyotypes showing D, E, F and $\mathrm{G}$ autosomes and a $\mathrm{Y}$ chromosome from two brothers (cases 7 and 8 ) with an unusually long $\mathrm{Y}$ chromosome. Top, case 7. Bottom, case 8 . 
of the ovary. The left testis was $1.5 \times 1.5 \times 1.0 \mathrm{~cm}$ in size and right one was very small in structure. Histologically they were remarkable by the occurrence of a bilateral gonadoblastoma. The testis showed undeveloped and atrophic seminiferous tubules, variable in size. Sertoli cells lining the tubules and undifferentiated germ cells, few in number, were found scattered taking a rosette or radial arrangement together with neoplastic cells in the form of nests. Interstitial cells showed relatively thick distribution in each tubule. Buccal cells showed a negative sex-chromatin pattern. Chromosome analyses based on leucocyte cultures revealed that this patient was characterized by a 45, XO/46, XY mosaicism (Fig. 3).

Two cases of phenotypic males (13 and 14) were chromosomally normal showing a 46, XY karyotype. One male with hypospadias (case 15) had an abnormally long Y chromosome, other elements being normal. The mean length of the $\mathrm{Y}$ corresponded to that of no. 18 chromosomes.

Out of the 5 phenotypic females here concerned, 4 (cases 16 to 19) were chromosomally normal, leaving one (case 20) with primary amenorrhoea who was characterized by short statue and eunucoid body proportion without any other Turner's stigmata. She was associated with a sex-chromosome mosaicism consisting of 45 , XO and $46, \mathrm{XX}$ cell lines at nearly equal frequency. Buccal mucosal smears proved a positive sex-chromatin pattern in 20 per cent of cells observed.

\section{DISCUSSION}

Among 20 cases of sexually abnormal subjects dealt with in the present study, 13 were found to have sex-chromosome abnormalities as follows: they are represented by 3 cases of Klinefelter's syndrome with a standard 47, XXY karyotype, one 48, XXXY (long) Klinefelter case, 2 mosaic Klinefelter cases, one with a $46, \mathrm{XY} / 47, \mathrm{XXY}$ and the other with a 46, XX/47, XXY complements, 5 males with an abnormally long $\mathrm{Y}$ chromosome, its length being different from case to case, 1 male pseudohermaphrodite with a 45 , XO/ 46, XY mosaic complex and 1 mosaic female having a 45, XO/46, XX constitution.

The three standard XXY Klinefelter cases were remarkable by some of clinical features characteristic of this syndrome, such as small atrophic testes showing poorly developed seminiferous tubules with an increase of Leydig cells, and high excretion of gonodotropin. Ferguson-Smith (1966) reported that ten patients with XXXY karyotype were all mentally retarded, some being quite severely. One prepuberal boy (case 4) in the present study characterized by a $48, \mathrm{XXXY}$ (long) karyotype, was mostly normal in clinical features except small penis, without severe mental retardation.

Various types of mosaic individuals have been reported to occur in chromatin-positive Klinefelter patients (Sasaki and Makino 1967). Among them, an XY/XXY mosaicism is most frequent. Generally there is a trend that the frequency of patients with microorchism, azoospermia and mental deficiency is slightly lower in the XY/XXY group than in the XXY group (Ferguson-Smith 1966). An XY/XXY mosaic case (case 5) here observed was indistinguishable from the XXY cases in general clinical features. Further, this patient showed only 20 per cent of XXY cells in cells so far observed. Skin and testis biopsies are requested to be scanned in this case. 
The XX/XXY mosaicism is known to be less common, or perhaps is less frequently detected, than the XY/XXY group (Ferguson-Smith 1966). The XX/XXY patient here studied was similar in several clinical features to the XXY Klinefelter cases. For the question of true hermaphroditism in the present case, the examination of testis biopsy may be requested.

An increase in maternal age has been noted in chromatin-positive Klinefelter's syndrome (Ferguson-Smith 1966): the mean maternal ages were 32.3 years for $176 \mathrm{XXY}$ patients, 31.3 years for $23 \mathrm{XY} / \mathrm{XXY}$ patients and 31.7 years for $3 \mathrm{XX} / \mathrm{XXY}$ patients. In this connection, a substantially high maternal age was evident in 3 of 6 cases in the present study: 48 years for case 1,45 years for case 5 and 37 years for case 6 . Of particular interest is that two of the three cases were mosaics with $\mathrm{XY} / \mathrm{XXY}$ and $\mathrm{XX} /$ $\mathrm{XXY}$ karyotypes, respectively. It is very probable that in those two cases the agedependent meiotic nondisjunction in the mother might have preceded the age-independent postzygotic nondisjunction, though there is no positive evidence for such an assumption.

Since the first report by Bender and Gooch (1961), a considerable number of cases of an unusually long $\mathrm{Y}$ chromosome has been available in the literature. It has been generally agreed that the increased length of the $\mathrm{Y}$ chromosome in man is an inheritable character, and that it is not necessarily associated with definite phenotypic anomalies (Makino and Takagi 1965, Sasaki and Makino 1967). In the present survey, six presumable infertile males including 3 cases with hypogonadism, and one case each with cryptorchism, hypospadias and Klinefelter's syndrome were found to have the long $\mathrm{Y}$ chromosome. Whether relatively frequent occurrence of the long $\mathrm{Y}$ carriers, 6 of 15 phenotypic males is associated, or not, with sexual hypoplasia and infertility is uncertain, because the long $\mathrm{Y}$ chromosome has been known in phenotypically normal and fertile males. Further the fact was presented that the length of the $\mathrm{Y}$ chromosome was dissimilar between two brothers (cases 7 and 8) who were suffered from hypogonadism. The chromosome conditions of their familial members, particularly of their fathers and brothers diagnosed as hypogonadism, are the subjects of special interest in future, now the study being in progress.

It has been reported that the clinical pictures of the $\mathrm{XO} / \mathrm{XY}$ mosaic patients are variable to a considerable extent, in comparison with those of other types of sex-chromosome abnormalities. Different phenotypic effects may depend upon the distribution of cells in various tissues and the time of formation of the $\mathrm{XO}$ cell population (Moore 1966). Some attempts of phenotypic classification of the $\mathrm{XO} / \mathrm{XY}$ mosaicism was made by Dave (1966). The XO/XY patient observed in the present study was legally a female, but clinically a male with small testes, despite of the presence of the uterus, fallopian tubes and vagina. On this basis, this patient was diagnosed as a male pseudohermaphrodite. Further it is interesting that the both testes of this patient were suffered from gonadoblastoma. Gonadal tumours have been known to occur in some patients with dysgenetic or underdeveloped gonads, involving XO/XY cases (Boczkowski 1967).

The XO/XX mosaics are common sex-chromosome abnormality in Turner's syndrome ranking next to the standard XO case. Generally they show less severely affected features than the XO patients (Miller 1964). It has been reported that the clinical spec- 
trum of the $\mathrm{XO} / \mathrm{XX}$ mosaicism is wide and varies from typical Turner's syndrome with many associated anomalies to cases with normal gonads and stature (Yunis 1965). The $\mathrm{XO} / \mathrm{XX}$ patient observed in the present study was rather normal in phenotype except primary amenorrhoea, underdeveloped uterus, relatively short stature with eunicoid proportion, though the gonad was not examined.

Mention was made by Makino $(1964,1966)$ that certain abnormal sexual chracters may result from some environmental factors which causes endocrine unbalance and affects the course of sexual differentiation and development in a certain stage after the genetic sex had been normally determined. The seven chromosomally normal cases may be those under a similar situation as above mentioned.

\section{SUMMARY}

Twenty patients associated with sex anomalies were screened for chromosome abnormalities. Among them, 13 cases were found to be chromosomally abnormal. They are 3 cases of Klinefelter's syndrome with a regular XXY sex-mechanism, 2 cases of Klinefelter's syndrome showing $\mathrm{XY} / \mathrm{XXY}$ and $\mathrm{XX} / \mathrm{XXY}$ cell mosaicisms respectively, 1 case of Klinefelter's syndrome with an XXXY (long) sex-mechanism, 1 case of male pseudo-hermaphrodite with an $\mathrm{XO} / \mathrm{XY}$ mosaicism, 1 case of primary amenorrhoea with an $\mathrm{XO} / \mathrm{XX}$ mosaicism, and 5 males with an unusually long $\mathrm{Y}$ chromosome. The remaining 7 cases did not deviate from a normal complement, being $46, \mathrm{XX}$ in females and $46, \mathrm{XY}$ in males.

\section{ACKNOWLEDGMENTS}

We express our gratitude to Professor Sajiro Makino for his guidance and important criticism, and to Dr. Motomichi Sasaki for his expert advice and suggestion. Thanks are also extended to Drs. Y. Abe, I. Amino, N. Hirota, K. Kawakura, H. Kishimoto, I. Makino, Y. Nakano, N. Ohashi, H. Ohmuro, H. Origasa, S. Shimamura, S. Sudo, H. Tanda for supplying the materials and clinical data for this study.

\section{LITERATURE CITED}

Bender, M. A., and P.C. Gooch, 1961 An unusually long human Y chromosome. Lancet 11: 463464.

Boczkowski, K., J. Teter, H. Tomaszewska, and J. Philip, 1967 Gonadoblastoma (Gonocytoma III) in a boy with XO/XY mosaicism. Acta Pathol. Microbiol. Scand. 71: 46-58.

Dave, M. J., 1966 Cytogenetic studies in 14 sexually abnormal patients. Cytologia 31: 11-18.

Ferguson-Smith, M. A., 1966 Sex chromatin, Klinefelter's syndrome and mental deficiency. In "The sex chromatin" (K. L. Moore, ed.) pp. 277-315. W. B. Saunders Co. Philadelphia and London.

Ikeuchi, T., and S. Fujimoto, 1966 A study of chromosome in ten sexuallya bnormal patients. J. Fac. Sci. Hokkaido Univ. Ser. VI, Zool. 16: 54-59.

Makino, S., 1964 Chromosomal studies in normal human subjects and in 300 cases of congenital disorders. Pt. I, II, III. Cytologia 29: 13-31, 115-150, 233-262. 
Makino, S., 1966 Chromosome studies in 150 sexually abnormal patients. (a summarized report). Pt. I-II. Cytologia 31: 309-374.

Makino, S., and N. Takagi, 1965 Some morphological aspects of the abnormal humal Y chromosome. Cytologia 30: 274-292.

Miller, O, J., 1964 The sex chromosome anomalies. Am. J. Obstet. Gynecol. 90: 1078.

Moorhead, P. S., P. C. Nowell, W. J. Mellman, D. M. Battips, and D. A. Hungerford, 1960 Chromosome preparations of leukocytes cultured from human peripheral blood. Exptl. Cell Res. 20: 613616.

Rothfels, K. H., and L. Siminovitch, 1958 Air-drying technique for flattening chromosomes in ammmalian cells grown in vitro. Stain Technol. 33: 73-77.

Sasaki, M., and S. Makino, 1967 Sex-chromosome abnormalities in man: a review. Gunma Symp. Endocrinol. 4: 3-22.

Shimba, H., S. Makino, M. Sasaki, M. C. Yoshida, and T. Ikeuchi, 1967 A chromosome study in 32 sexually abnormal patients. Japan. J. Genetics. 42: 307-315.

Yunis, J. J., 1965 Human chromosome in disease. In "Human chromosome methodology" J. J. Yunis, ed. pp. 187-237. Acad. Press, New York. 